\title{
Value of MT inversions for geothermal exploration: accounting for multiple interpretations of field data \& determining new drilling locations
}

\author{
Whitney J. Trainor-Guitton ${ }^{1 *}$, G. Michael Hoversten ${ }^{2}$, Gregg Nordquist ${ }^{3}$, Rindu Grahabhakti Intani ${ }^{4}$
}

Keywords: value of information, resource assessment, magnetotellurics

\begin{abstract}
We present a value of information analysis for MT data for locating high steam flow regions of a geothermal resource. The high electrical conductivity feature in volcanic geothermal settings, known as the clay cap, can be indicative of geothermal alteration occurring just above the resource. We demonstrate how several alternative interpretations of the clay cap from one 3D electrical conductivity model can be used to estimate the value of geophysical information. Our results indicate that the final VOI estimate was not strongly dependent on the different interpretations of the clay cap. Additionally, we demonstrate how these VOI evaluations can be used to guide future drilling locations.
\end{abstract}

\section{INTRODUCTION}

The value of information (VOI) quantifies how relevant and reliable any particular information source is, and quantifies its value when making a decision with an uncertain outcome. VOI can be used to justify the costs of collecting and processing the planned data. It has been used in oil exploration (see review by Bratvold et al., 2009). We apply it here to geophysical data from a geothermal field. Previous work (Trainor-Guitton et al., 2013a,b) tested the applicability for geothermal exploration using synthetic datasets.

VOI is a method from the field of decision analysis. Decision analysis concepts are often described in terms of lotteries and prizes (Pratt et al., 1995). By choosing to drill or not, a decision maker is choosing whether or not to participate in a lottery with certain perceived chances of winning a prize (drilling into a profitable reservoir); however, this lottery also involves the chances of losing money (drilling into an uneconomic or nonexistent reservoir). VOI estimates the possible increase in expected utility (winning a lottery with a bigger prize) by gathering information before making a decision, such as where or if to drill a production well. In its simplest form, the VOI equation can be expressed as: 


$$
V O I=\max \left(V_{\text {with information }}-V_{\text {prior }}, 0\right)
$$

32 where $\mathrm{V}$ is the value, the metric used to quantify the outcome of a decision. The higher the value, the more

33 "successful" an outcome of a decision is. Therefore, value is the revenue gained minus the costs incurred 34 for any particular decision action taken. The simplest representation of the decision in geothermal 35 exploration is "to drill or not" for one particular location; if heat, permeability and fluids exist in that 36 location, then the value outcome of that decision will be high. Otherwise, the value outcome will be a 37 monetary loss.

38 We consider how well the clay cap, as delineated by a 3D MT data inversion, can indicate magnitude of the 39 steam flow by utilizing a dataset from an operating geothermal field. The electrically conductive materials 40 imaged by MT are created by geochemical alteration when hot fluids and gases circulate within subsurface 41 geologic units (Gunderson et al., 2000). However, if the hot fluid source ceases to exist, the electrically 42 conductive material will remain, thus a clay cap does not guarantee current geothermal activity (Karlsdóttir 43 et al., 2012). In this study, the clay cap, defined by electrical conductivity, is used as a proxy for the 44 presence of smectite clay, which is more electrically conductive.

45 The contributions presented in this paper are twofold. First, our work illustrates the implementation of a 46 VOI methodology given the uncertainties of geothermal exploration and multiple interpretations of the clay 47 cap from a 3D MT inversion. We utilize an existing dataset of steam flow measurements to deduce trends 48 between steam flow and electrical conductivity, thereby using the past performance of the geophysical 49 technique to predict steam flow. We produce six sets of VOI results, which correspond to the two clay cap 50 interpretations, two possible prior uncertainty descriptions and two possible economic consequence 51 structures. The VOI's produced can be used to determine if MT should be collected again in a field with 52 similar geological and geophysical attributes. The second type of results presented here demonstrate how 53 the probabilistic VOI evaluations can serve as a guide on deciding where to drill new production wells in undeveloped areas given that the MT information has already been collected in that area.

The paper is organized as follows. First the steam flow and MT data sets are described. Then we describe how the 3D cube of electrical conductivity is used to infer the location and margins of the clay cap: the potential margins or boundaries of the geothermal reservoir. Third, we will describe the different set of assumptions used to determine two different clay caps and the colocation between the electrical conductivity of the clay cap and a steam flow measurement. The various conductivity and spatial thresholds produce two interpretations of the "calibrated dataset." Fourth, these interpretations will provide estimates of the MT's reliability to delineate the boundaries of the geothermal reservoir. Finally, we will use these reliabilities to 1) calculate VOI's (values of information) of MT and 2) provide guidance on where future drilling should be focused. 


\subsection{Darajat geothermal field}

Darajat is a vapor geothermal field located in West Java, Indonesia. It is located about $150 \mathrm{~km}$ to the southeast of Jakarta and has an elevation ranging from 1,750 to 2,000 meters above sea level. First production from the field was started in 1994 with installation of a 55 MW plant. Additional capacity was added in 2000 and 2007 to bring the total production capacity to $271 \mathrm{MW}$ from three power plants.

The Darajat geothermal field is located along a range of Quaternary volcanic centers in West Java. It is spatially associated with an eroded andesitic stratovolcano, Gunung Kendang. The reservoir is predominantly comprised of thick lava flows and intrusions in a stratovolcano central facies, with relatively higher porosity, thick pyroclastic sequences of proximal to medial facies that were deposited more toward the margins. Structures trend predominantly NE-SW but also include N-S and NW-SE trending faults (Rejeki et al., 2010).

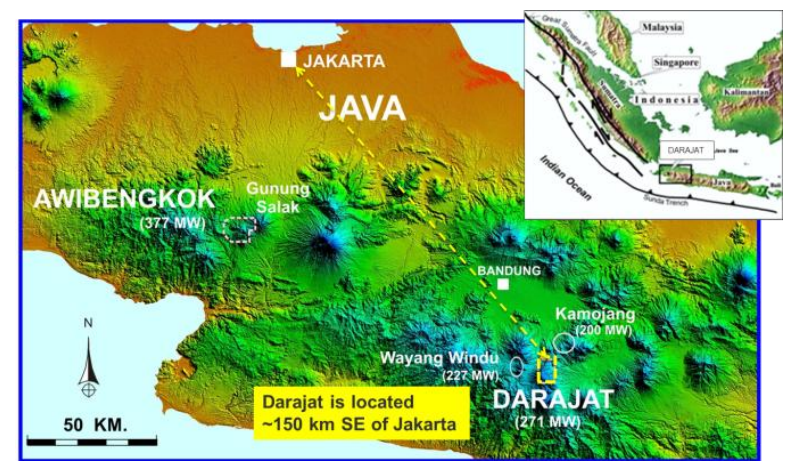

Figure 1: Location of the Darajat geothermal field in West Java

\subsection{Data sets used in this study}

\section{$\underline{1.2 .1 \text { Steam flow measurements }}$}

The steam flow data approximately spans an area of $2.6 \mathrm{~km}$ by $4.2 \mathrm{~km}$ and a depth range of $600 \mathrm{~m}$ to $1800 \mathrm{~m}$ below the surface. Figure 2 displays a histogram of these steam flow measurements. The steam flow measurements are the average production over one year for 27 different wells, where the production is the composite flow for all feed zones from each well. Four of these wells were drilled near to or outside of the geothermal field and are characterized by production rates of $<5 \mathrm{~kg} / \mathrm{s}$. As many of these wells were drilled after the MT data were collected, the wells were drilled with the intention of placing them where steam flow was interpreted to be high. Therefore, a bias exists in the data. 


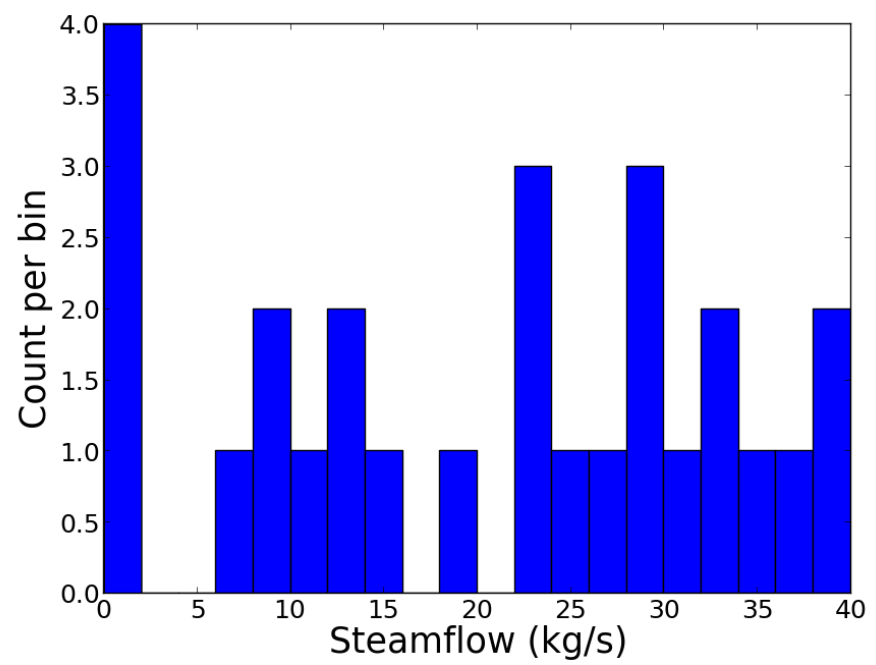

Figure 2: Histogram of steam flow data from 27 wells.

88 For this work, we categorized the steam flow magnitude into seven groups or bins, represented by $\theta_{\mathrm{i}}$ :

$$
\theta_{i} i \in\left\{\begin{array}{cc}
7, & \theta \geq 30 \mathrm{~kg} / \mathrm{s} \\
6 & 25 \leq \theta<30 \mathrm{~kg} / \mathrm{s} \\
5, & 20 \leq \theta<25 \mathrm{~kg} / \mathrm{s} \\
4, & 15 \leq \theta<20 \mathrm{~kg} / \mathrm{s} \\
3, & 10 \leq \theta<15 \mathrm{~kg} / \mathrm{s} \\
2, & 5 \leq \theta<10 \mathrm{~kg} / \mathrm{s} \\
1, & 0 \leq \theta<5 \mathrm{~kg} / \mathrm{s}
\end{array}\right.
$$

89 We define our prior uncertainty with respect to steam flow production using these steam flow categories.

90 Let us represent this by

$$
\mathbf{z}\left(\theta_{i}\right) \quad i=1, \ldots, 7
$$

91 where vector $z$ represents the non-dimensional steam flow categories that may be realized from production 92 wells. Future work could incorporate spatial aspects of this steam flow possibility. The steam flow 93 categories can be used to represent the economic (value) outcome of a drilling decision at any location $94(x, y, z)$.

95 Table 1 summarizes the probability of occurrence for each of the steam flow categories $(\operatorname{Pr}(\Theta=$ $\left.96 \theta_{i}\right)$ ) according to (a) the data and (b) another hypothetical prior probability that will be used later for the 97 value of information analysis. These probabilities should be derived from expert opinion and all other data 98 available for the particular site. The priors in column $\mathrm{b}$ are chosen for demonstration purposes and are not 99 related to the Darajat field per se. Note that for the prior probabilities based on the steam flow data (Table 100 1a), the probability for the highest steam flow category, $(\operatorname{Pr}(\Theta>30))$, is high at $26 \%$, due to the drilling 101 bias mention earlier. The alternative prior represents scenarios where the risk of a dry hole, $\operatorname{Pr}(\Theta<5))$, is 102 high at $40 \%$, and hence a costly outcome is more likely than other steam flow outcomes. This may be more 
representative of geothermal fields in the early exploration stages, with few sources of information available.

Table 1: Prior probabilities of steam flow categories according to the data and other projections

\begin{tabular}{|c|c|c|}
\hline $\begin{array}{l}\downarrow \text { Steam Flow Rate } \\
(\mathrm{kg} / \mathrm{s})\end{array}$ & $\begin{array}{c}\text { a) Percentage } \\
\text { of steam flow } \\
\text { data in each } \\
\text { category }\end{array}$ & $\begin{array}{c}\text { b) Alternate } \\
\text { Prior }\end{array}$ \\
\hline$\theta_{\mathrm{i}}>30$ & $26 \%$ & $10 \%$ \\
\hline $25 \leq \theta_{\mathrm{i}} \leq 30$ & $15 \%$ & $10 \%$ \\
\hline $20 \leq \theta_{\mathrm{i}} \leq 25$ & $15 \%$ & $10 \%$ \\
\hline $15 \leq \theta_{\mathrm{i}} \leq 20$ & $7 \%$ & $10 \%$ \\
\hline $10 \leq \theta_{\mathrm{i}} \leq 15$ & $11 \%$ & $10 \%$ \\
\hline $5 \leq \theta_{\mathrm{i}} \leq 10$ & $11 \%$ & $10 \%$ \\
\hline$\theta_{\mathrm{i}} \leq 5$ & $15 \%$ & $40 \%$ \\
\hline
\end{tabular}

\subsubsection{Magnetotellurics}

The MT data used for this analysis consists of 85 remote referenced stations that were distributed over and outside the boundaries of the Darajat geothermal field. The data were collected in 1996-97 and 2004 and were used to interpret the distribution and extensions of the electrically conductive clay cap beyond the first development area (Rejeki et al., 2010). For the 3D inversion of the data set, the off-diagonal impedances between 100 seconds and 100 Hertz were inverted using the 3D algorithm of Newman and Alumbaugh (2000). The impedance errors derived from the multi-station robust processing were used, subject to a $10 \%$ error floor. The starting model was a $10 \Omega \mathrm{m}$ half-space beneath the topography. The inversion reduced the RMS data misfit from 87 to 1.3 (Trainor-Guitton et al., 2015).

\section{METHODOLOGY}

Our methodology estimates the prediction power of MT given a colocated steam flow dataset. First, we consider the decision of "to drill or not," and we make several evaluations of the efficacy of MT via several interpretations of the MT inversion model. It is possible to extend the methodology to the more complex decision of "where to drill"(Trainor-Guitton et al., 2014). We assume that the decision outcome only depends on the possible steam flow of a reservoir.

\subsection{Interpretations of clay cap: different conductivity thresholds}

We have one 3D model of conductivity inverted from the MT dataset described above which overlies where the steam flow measurements were made. First, we use only this inversion model to determine possible relationships between the electrical conductivity property and the steam flow magnitude. Typically, the high conductivity layer can be used to estimate the likely margins of the geothermal system (Cumming, 
2009). We attempt to assess whether the thickness and conductivity information of the clay cap can be used to distinguish between higher and lower steam flow.

As we assume that the "clay cap" margins can be used to infer the boundaries of the geothermal resource, we define a conductivity threshold in order to delineate the location and thickness of the clay cap. We use a bottom threshold value of $\sigma=0.12 \mathrm{~S} / \mathrm{m}$. Thus, a top and bottom surface is defined where the electrical conductivity begins to decrease from the threshold value of $\sigma=0.12 \mathrm{~S} / \mathrm{m}$. The resulting cap is pictured in Figure 3.

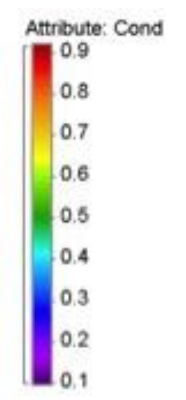

a)

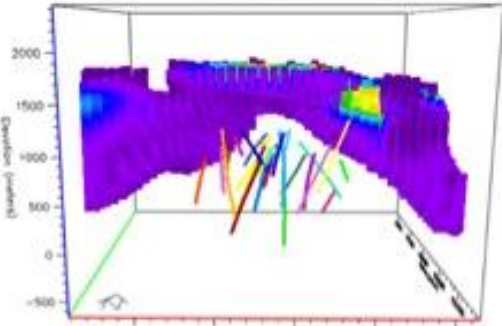

Figure 3: a) Cross sectional view and b) top view of clay, defined by threshold $\sigma=0.12 \mathrm{~S} / \mathrm{m}$. Wells
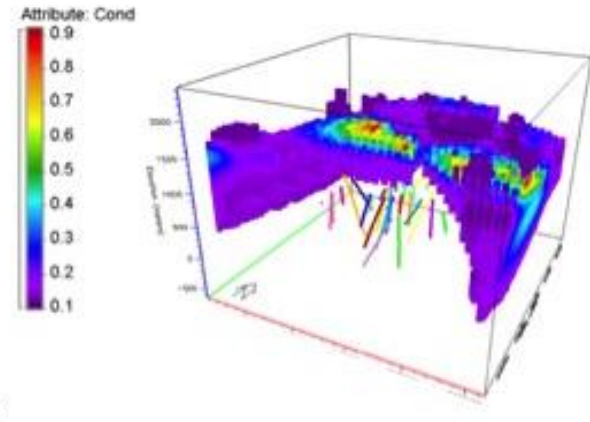
containing steam flow measurements shown in multicolor.

\subsubsection{Defining "colocated" electrical conductivity and steam flow}

Next, we determine which conductivity locations within the clay cap that can be correlated with the steam flow measurements. We suggest that steam flow flows closer to the cap are more likely to influence the electrical conductivities and geometry of the clay cap. Therefore, we expect a stronger relationship between the steam flow measurements that are closer to the clay cap.

We begin by defining $750 \mathrm{~m}$ as the maximum distance between a steam flow measurement and any point within the clay cap. We choose this distance because it represents the lower quartile of all distances between the clay cap conductivities and steam flow locations. Figure $5 \mathrm{~b}$ displays the midpoint of the steam producing zone of Well 15 as a red box along the well path (red) and the conductivity values of the clay cap. Midpoints were both calculated as the straight mid-point between the top and bottom feedzones and a production-weighted midpoint; we found that the results were not sensitivity to the different midpoint definitions. Results presented use the unweighted midpoint.

To illustrate the inverse relationship of steamflow and conductance, we plot the average of the neighboring conductances to each steamflow point in Figure 4. First, the location of the closest conductivity measurement to the well midpoint is determined. Then, the neighboring conductivity values in the clay cap are averaged within a radius of $100 \mathrm{~m}$ to compare to the steam flow of that well. Figure $5 \mathrm{~b}$ displays only the conductivities measurements that are within $100 \mathrm{~m}$ (values used in the average) of the closest conductivity point for Well 15. 


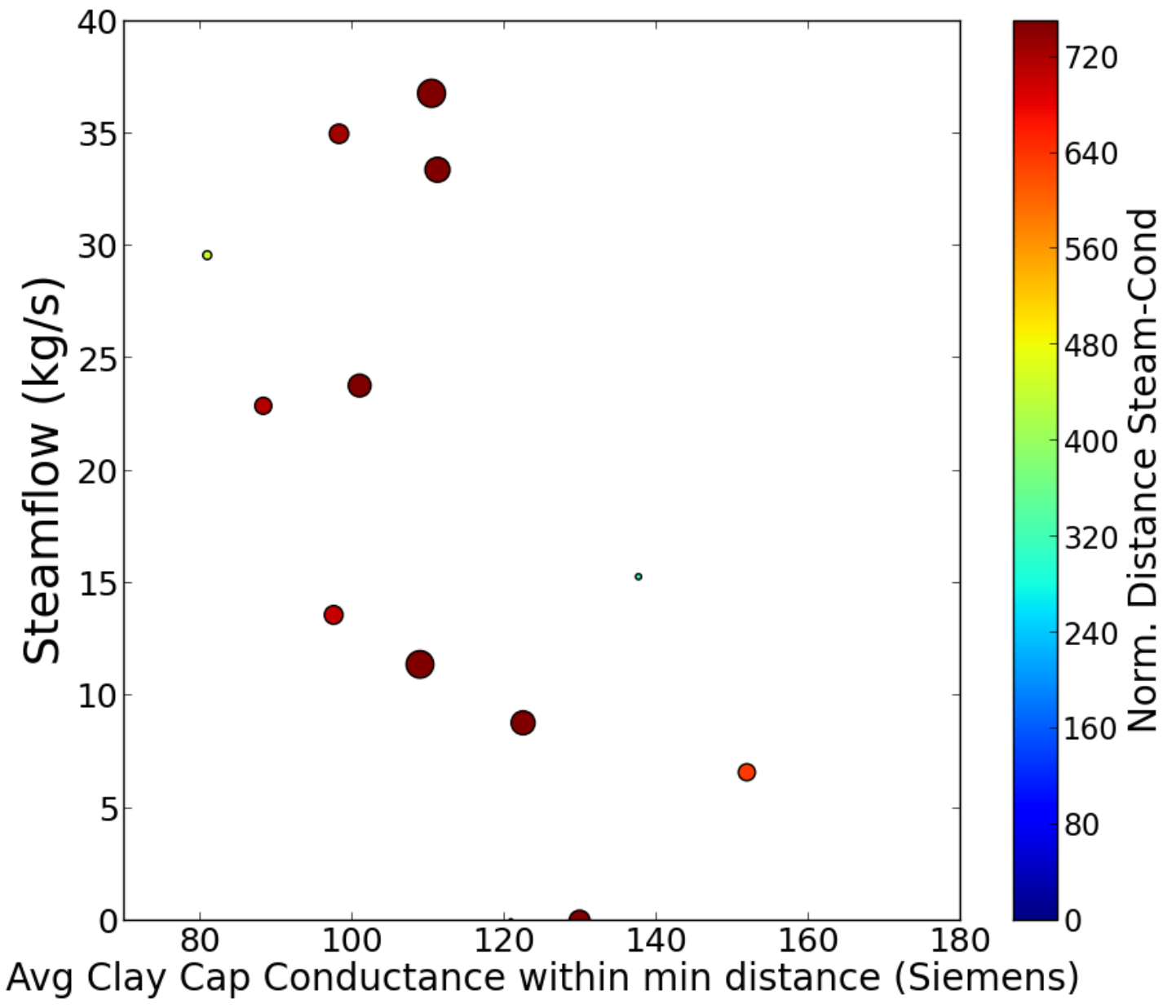

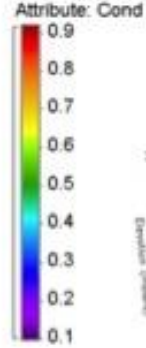

a)

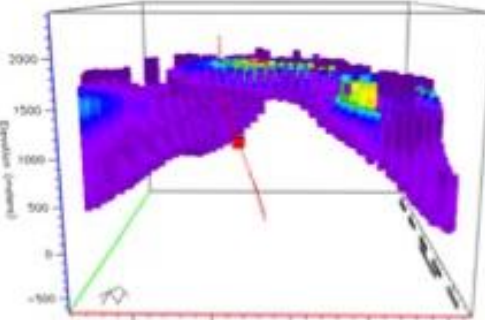

$+$

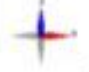

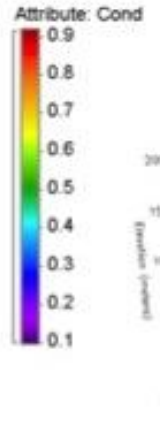

b)
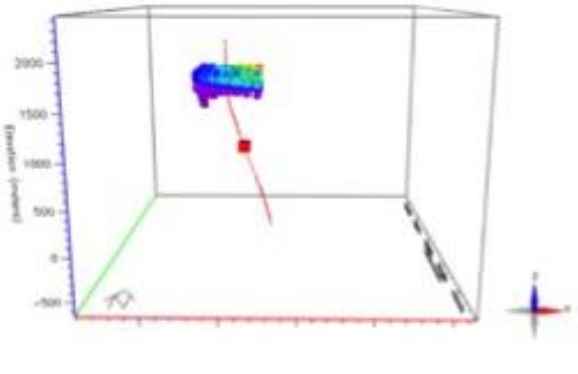

160 Figure 5 : a) Well 15 mid-point (red box along red path) with conductivities of clay cap. b) Only the conductivities within $100 \mathrm{~m}$ of the closest conductivity to Well 15 midpoint 
163 Fifteen of the 27 steam flow measurement locations were within the maximum threshold of $750 \mathrm{~m}$. The 12

164 wells that were far from the clay cap (not used in the calibration) were very deep wells and had mean and 165 median values of 19.6 and $23.45 \mathrm{~kg} / \mathrm{s}$ respectively. The statistics of the conductances and their "colocated" 166 steam flow categories are plotted in the box plot of Figure 6, where the steam flow categories' median 167 conductance is plotted as a red vertical line, the geometric mean as a star, the quartile range is represented 168 by the blue box, the "whiskers" (dashed lines) represent 1.5 the range of the data, and finally outliers are 169 red circles that are beyond these whiskers.

171 The clay cap for this analysis is defined on the basis of conductivity, and therefore it is expected to 172 dominantly represent the distribution of smectite, which is more electrically conductive. It is expected that 173 higher steam flow will also result in greater temperatures $\left(>200^{\circ} \mathrm{C}\right)$ to contact the rock, which will alter the 174 smectite clay to illitic or chloritic clay (Ussher et al., 2000). Illitic or chloritic clays are less conductive and 175 therefore not included as part of the clay cap. Therefore, the clay cap will appear to thin at locations with 176 higher steamflow. Thus, there is a negative correlation between steam flow and conductance (the product of 177 conductivity and thickness), which is dominated by the thickness. If the interpreted clay cap based on the 178 MT data is capturing only the highly conductive smectite, one would expect a shallower base and a 179 thinning of the clay cap over areas where the flow, permeability, and temperature are higher. 180 Therefore, we only consider and include the conductance (not conductivity or thickness alone) for the next 181 two interpretations of clay cap for comparison with the steam flow measurements.

182 With the exception of the $15-20 \mathrm{~kg} / \mathrm{s}$ category, generally lower conductance values correlate with higher 183 steam flow rates. The $15-20 \mathrm{~kg} / \mathrm{s}$ category has only 10 data points. Conversely, the highest steam flow 184 category has the largest range and most conductance data points, as expected since wells are preferentially 185 sampled to high steam flow areas. Also, the 3 wells with the highest rates are located near the clay cap 186 margin, where it thickens significantly. The negative correlation of steam flow with conductance (which is 187 dominated by the thickness given the relative magnitude of thickness versus conductivity) is expected since 188 greater temperatures $\left(>200^{\circ} \mathrm{C}\right)$ are often shallower over the center of the geothermal field (Rejeki et al., 189 2010). The shallow high temperatures tend to thin the conductive layer due to the highly conductive 190 smectite clays altering into more resistive illitic or chloritic clays (Ussher et al., 2000). 


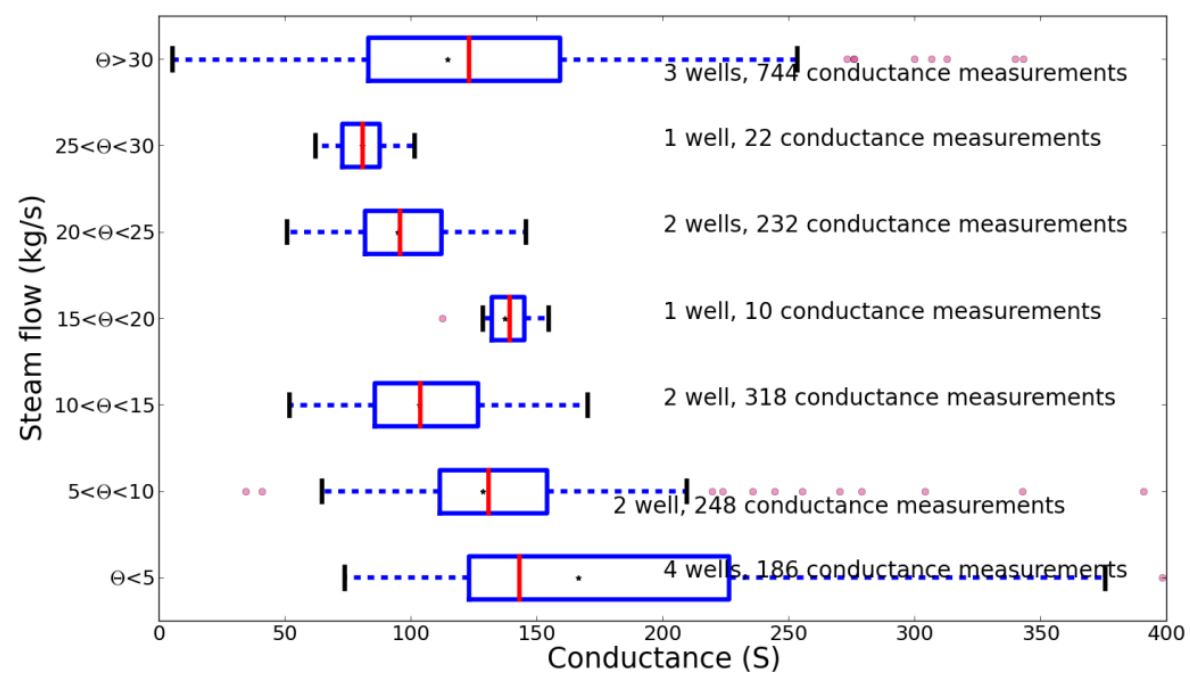

193 Figure 6: Box-whisker plot showing the median (red), interquartile range (solid blue) and 1.5 the range (dashed blue) of conductance measurements "colocated" with the 7 different steam flow categories. From clay cap interpreted with the $0.12 \mathrm{~S} / \mathrm{m}$ threshold.

Several interpretations of the clay cap (a 3D feature) are possible and may result in different estimates of the effectiveness of the MT technique to detect electrically conductive targets, which can be indicative of potential geothermal resources. We repeat the above using a threshold of $0.10 \mathrm{~S} / \mathrm{m}$. This clay cap, shown in Figure 7 is slightly thicker than the clay cap defined by the threshold of $0.12 \mathrm{~S} / \mathrm{m}$ (Figure 3). This thicker clay cap produces more pairs of steam flow/conductivity location pairs, as the midpoints of wells will be deemed within the defined maximum distance of $750 \mathrm{~m}$.

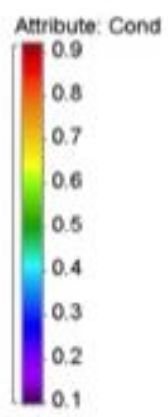

a)
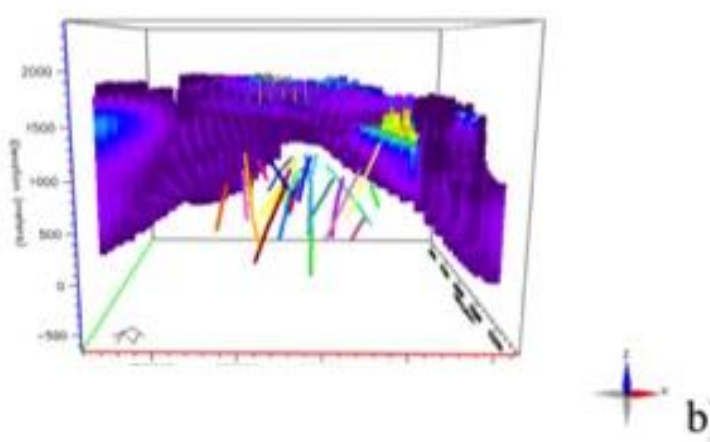

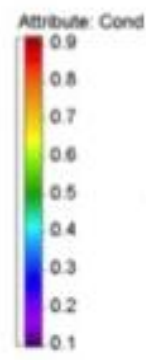

b)

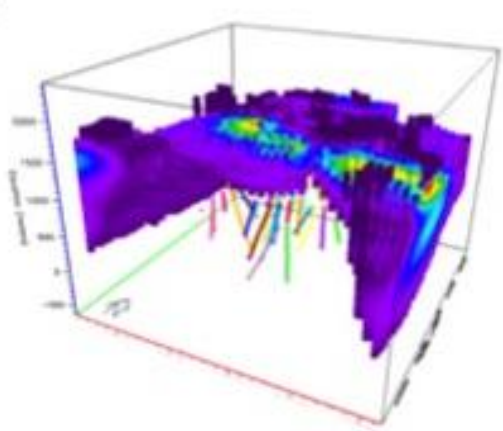

Figure 7: Cross sectional view of clay cap defined by threshold $\sigma=0.10 \mathrm{~S} / \mathrm{m}$. Wells containing steam flow measurements shown in multicolor

The box and whisker plots of the conductances associated with the 7 different steam flow categories for the clay cap defined with a threshold of $0.10 \mathrm{~S} / \mathrm{m}$ are displayed in Figure 8. Figure 8 compared to Figure 6 has 
a smaller range of conductance for the highest steam flow category but also shows a similar negative correlation between steam flow and conductance. The higher conductivity threshold of $0.12 \mathrm{~S} / \mathrm{m}$ (Figure 6) results in a thinner clay cap, thus smaller conductance values (10-250S) and outliers $>350 \mathrm{~S}$, whereas conductances in Figure 8 are $\sim 40-250$ S and there no outliers $>350$ S.

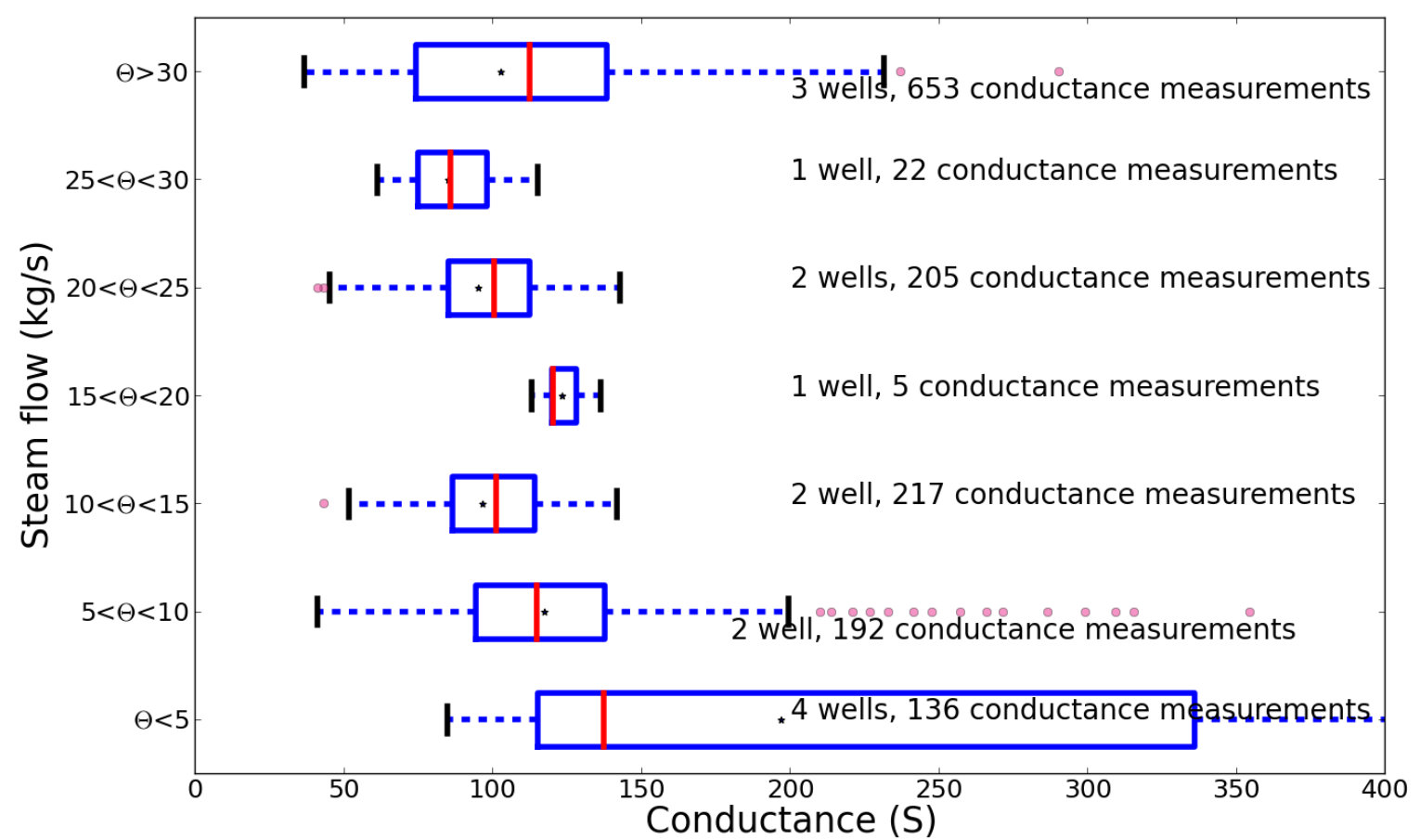

214 Figure 8: Box and whisker plot showing the median (red), interquartile range (solid blue) and 1.5 the range (dashed blue) of conductance "colocated" with the 7 different steam flow categories. From clay cap interpreted with the $0.10 \mathrm{~S} / \mathrm{m}$ threshold.

\section{2.3 Data reliability/likelihood estimations from conductance-steam flow calibrations}

As described in the Introduction, a data reliability or likelihood is necessary to evaluate VOI. The reliability quantifies the uncertainty in the relationship between the electrical conductance and the steam flow magnitude. We have two interpretations of the clay cap from the 3D MT inversion. In order to have sufficient measurements to compute statistics, we will use all conductance measurements underlying the box and whisker plots of Figure 6 and Figure 8. Therefore, the data reliabilities will be computed corresponding to the two clay cap calibrations (Figure 6 and Figure 8).

Figure 9 and Figure 10 depict the counts of every conductance measurement from Figure 6 and Figure 8: respectively the clay caps defined by a threshold of $0.12 \mathrm{~S} / \mathrm{m}$ and $0.10 \mathrm{~S} / \mathrm{m}$. The counts in the histograms are represented graphically by the blue vertical bars and mathematically by $c_{i j}$, where $\mathrm{c}$ is the total number 
228 of measurements that fall within conductance bin $j$ and are associated with one of the seven steam flow

229 categories $i$ (Equation 2). We will describe the red lines in the next section (Section 2.4).

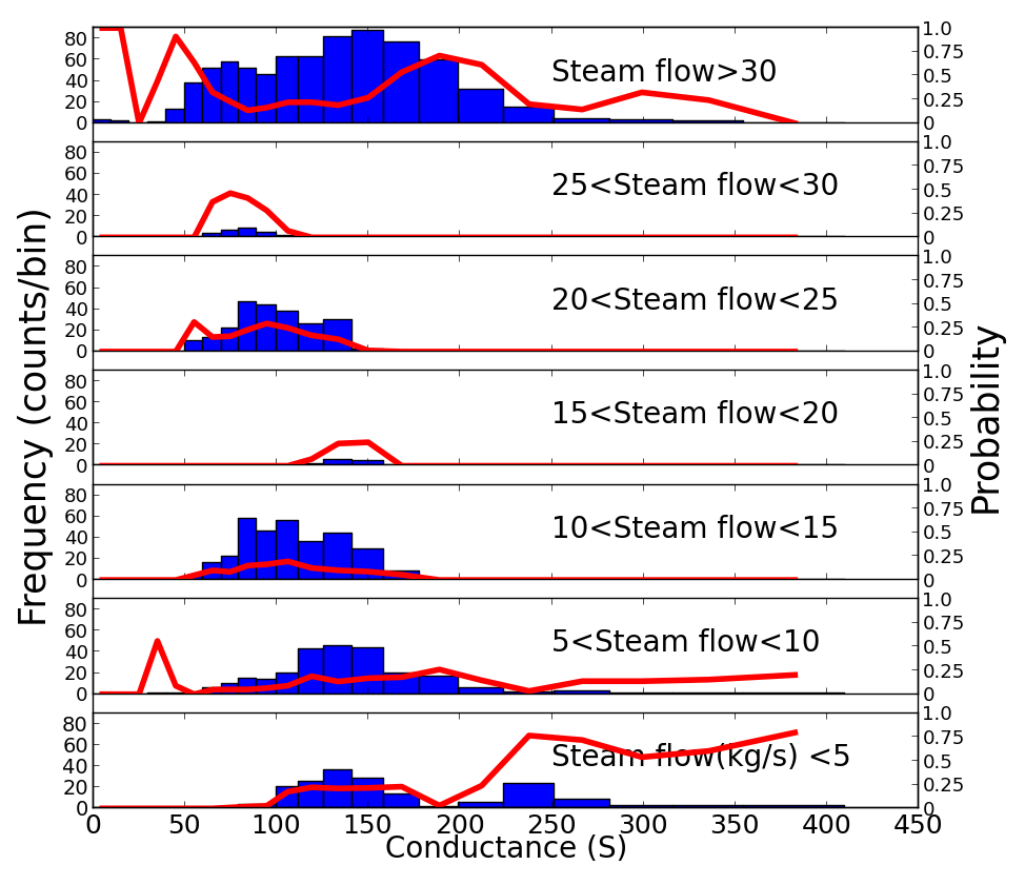

231 Figure 9: Counts (bars) and posteriors (red lines) for the clay cap interpretations defined at 0.12 S/m.

232 The sum of the posterior across the steam flow categories (vertically for each conductance bin) equals $100 \%$. 


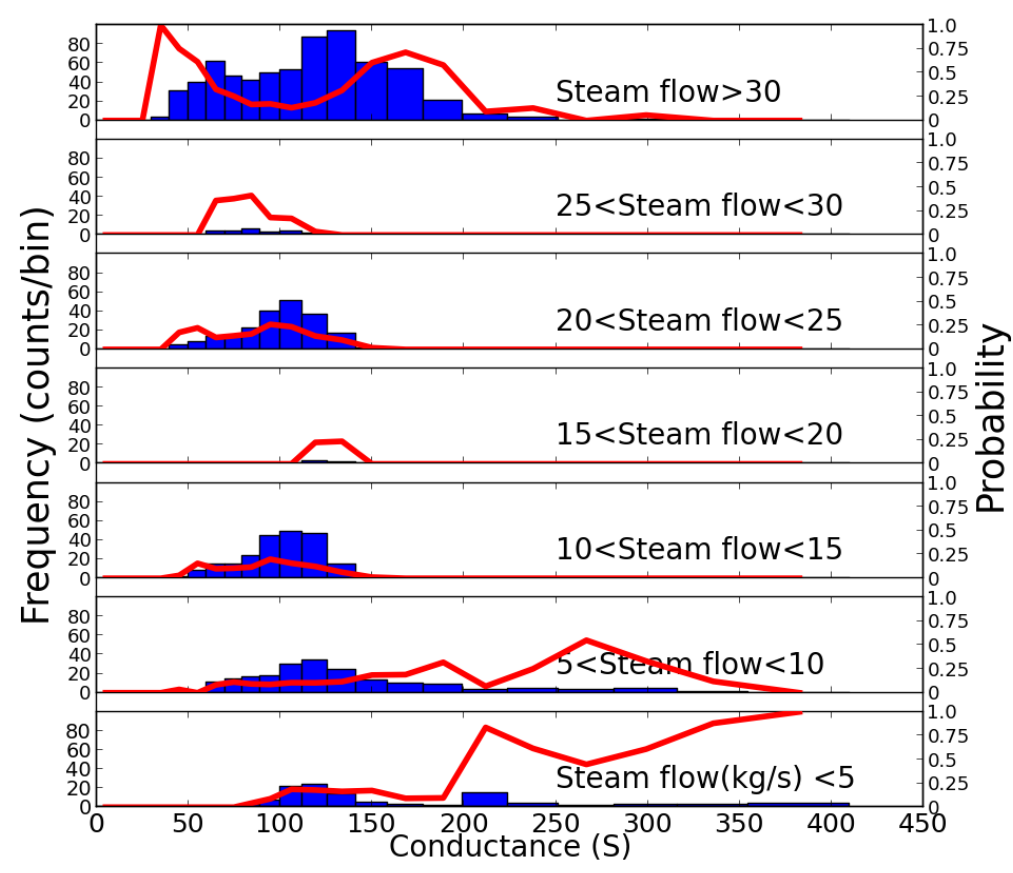

Figure 10: Counts (bars) and posteriors (red lines) for the clay cap interpretations defined at 0.10 $\mathrm{S} / \mathrm{m}$. The sum of the posterior across the steam flow categories (vertically for each conductance bin)

The data likelihood (also referred to as the data reliability) defines how likely a conductance bin is within a particular (known) steam flow category $\left(\theta_{i}\right)$. Therefore, the counts in bin $i j$ are normalized by the total number of measurements in that steam flow category (indice $i$ or horizontally for Figure 9). For this example, the notation of the data likelihood and its calculation is:

$$
\begin{gathered}
\operatorname{Pr}\left(G=g_{j} \mid \Theta=\theta_{i}\right)=\frac{c_{i j}}{\sum_{i} c_{i j}} \\
i=\{1,2,3,4,5,6,7\} \quad j=1, \ldots, J
\end{gathered}
$$

243 where the electrical conductance is represented by $\mathrm{g}$. The denominator, $\sum_{i} c_{i j}$ represents normalization by 244 the sum of all data points within a steam flow categories $\left(\theta_{i}\right)$. The actual likelihood values are not shown in 245 Figure 9 and Figure 10, but the height of the bars are relative representations of the likelihood since they 246 show the counts for each of the 7 steam flow categories. categories

249 Next, we want to establish the information posterior, which establishes a "misinterpretation rate" or how 250 uniquely a conductance bin can distinguish between any of the steam flow categories $\theta_{i}$. According to 
251 Bayes law, the posterior $\left(\operatorname{Pr}\left(\Theta=\theta_{i} \mid G=g_{j}\right)\right.$ in Eqn. 5 below $)$ is equal to the product of the prior probability $\left(\operatorname{Pr}\left(\Theta=\theta_{i}\right)\right)$ and the likelihood $\left(\operatorname{Pr}\left(G=g_{j} \mid \Theta=\theta_{i}\right)\right)$ scaled by the marginal $\left(\operatorname{Pr}\left(G=g_{j}\right)\right)$ :

$$
\begin{aligned}
\operatorname{Pr}\left(\Theta=\theta_{i} \mid G=g_{j}\right)=\frac{\operatorname{Pr}\left(\Theta=\theta_{i}\right) \operatorname{Pr}\left(G=g_{j} \mid \Theta=\theta_{i}\right)}{\sum_{k=1}^{N+1} \operatorname{Pr}\left(\Theta=\theta_{k}\right) \operatorname{Pr}\left(G=g_{j} \mid \Theta=\theta_{k}\right)} \\
=\frac{\operatorname{Pr}\left(\Theta=\theta_{i}\right) \operatorname{Pr}\left(G=g_{j} \mid \Theta=\theta_{i}\right)}{\operatorname{Pr}\left(G=g_{j}\right)} i=\{1,2,3,4,5,6,7\} j \\
=1, \ldots, J
\end{aligned}
$$

253 The corresponding posteriors of the different conductance bins for the two clay cap calibrations are the solid red lines in Figure 9 and Figure 10. When the posterior is close to 1 (right hand y-axis label), this indicates that the data in that conductance bin is more informative (the misinterpretation rate is lower). The posteriors in Figure 9 and Figure 10 were calculated using the prior according to the data (Table 1a). For conductance values that were not represented in each of the particular calibration data sets (e.g. where no bars exist), the posterior probability is distributed according to the prior probability across the 7 steam flow bins.

Visually, the red posterior (steam flow $>30 \mathrm{~kg} / \mathrm{s}$ ) from the clay cap defined by the $0.12 \mathrm{~S} / \mathrm{m}$ threshold (top of Figure 9) has a high posterior $(\sim 1)$ value for the conductance bins at $\mathrm{G}<25 \mathrm{~S}$. This will contribute to a higher VOI evaluation, since this conductance range will uniquely distinguish this high steam flow category. At the same conductance bin and steam flow category from the $0.10 \mathrm{~S} / \mathrm{m}$ clay cap, the posterior is zero: no conductances this low were associated with these steam flow magnitudes. The other important difference between the two posteriors is in the conductance range of 275-400 S. The posterior from the higher clay cap threshold (Figure 9) ranges between 10-30\% for this conductance range; in contrast, the posterior from the lower clay cap threshold (Figure 10) is zero for these high conductances. Thus in this conductance range, the posterior from the lower clay cap threshold provides more discriminating relationship between the different steam flow categories. The VOI calculations will account for this, as seen in the next section.

\section{VOI CALCULATION: DESCRIPTION \& RESULTS}

273 This section describes the calculations necessary to estimate the value of imperfect information using the 274 information posteriors. First, the $\mathrm{V}_{\text {prior }}$ or the prior value is described.

\section{1 $\mathrm{V}_{\text {prior }}$ : the best decision option given prior uncertainty}

We will now describe how each prior model is linked to possible economic outcomes. This will be summarized in the quantity $\mathrm{V}_{\text {prior }}$, which translates our prior uncertainty (our current state of information) into an expected (or average) outcome from our decision. 
279 Recall that decision analysis frames the decision as the chance to enter the geothermal lottery with 280 perceived chances of winning a prize (e.g. drilling into a profitable reservoir). By utilizing $\mathrm{V}_{\text {prior }}$, a decision281 maker can logically determine when one should participate in this lottery given both the prior uncertainties 282 and possible gains and losses. The value metric allows for comparison between outcomes from different 283 decision alternatives, which can be represented by function $d_{a}$.

$$
\begin{gathered}
v_{a}\left(\theta_{i}\right)=d_{a}\left(\mathbf{z}\left(\Theta=\theta_{i}\right)\right) \\
a=1,2 \quad i=1, \ldots, 7
\end{gathered}
$$

284 We assume only 2 possible alternatives $(\mathrm{a}=1$ or 2$)$ : drill/produce the reservoir or do nothing. Table 1 285 defines the 14 possible outcomes, which is a result of these 2 decision alternatives and the 7 possible steam 286 flow categories. The columns represent the decision alternatives $(a=1$ and $a=2)$ and the rows the different 287 steam flow categories $\left(\theta_{i}\right)$.

Table 2: Table of nominal value outcomes for the 2 possible decision options (columns) and 7 possible economic viability categories of the unknown subsurface (rows).

\begin{tabular}{|c|c|c|}
\hline $\begin{array}{l}\text { Decision option } \rightarrow \\
\downarrow \text { Steam Flow Rate } \\
(\mathrm{kg} / \mathrm{s})\end{array}$ & $\begin{array}{c}v_{a=1}^{(t)}\left(\theta_{i}\right) \\
\mathrm{a}=1 \\
(\text { drill under } \\
\text { cap })\end{array}$ & $\begin{array}{c}v_{a=2}^{(t)}\left(\theta_{i}\right) \\
\mathrm{a}=2 \\
(\mathrm{do} \\
\text { nothing })\end{array}$ \\
\hline$\theta_{\mathrm{i}}>30$ & $\$ 700,000$ & $\$ 0$ \\
\hline $25 \leq \theta_{\mathrm{i}} \leq 30$ & $\$ 300,000$ & $\$ 0$ \\
\hline $20 \leq \theta_{\mathrm{i}} \leq 25$ & $\$ 125,00$ & $\$ 0$ \\
\hline $15 \leq \theta_{\mathrm{i}} \leq 20$ & $\$ 40,000$ & $\$ 0$ \\
\hline $10 \leq \theta_{\mathrm{i}} \leq 15$ & $\$ 0$ & $\$ 0$ \\
\hline $5 \leq \theta_{\mathrm{i}} \leq 10$ & $-\$ 200,000$ & $\$ 0$ \\
\hline$\theta_{\mathrm{i}} \leq 5$ & $-\$ 500,000$ & $\$ 0$ \\
\hline
\end{tabular}

Table 2 represents hypothetical, monetary values that could represent relative gains (payouts-- shown in 292 black-- when you drill a well with economic production rates) or losses (loss on investment -shown in red-when you drill an uneconomic well). Specific (and more realistic) gains and losses for a particular field site can be easily substituted in Table 1 and into the methodology; the values. This would be necessary to use the resulting VOI's to determine if a particular data type is worth purchasing at a specific field site. The values in Table 1 are simply for demonstration purposes so that the behavior of the VOI quantities can be visualized. These values will vary with the cost of drilling and steam price. 
299 All the necessary quantities have been introduced to calculate $V_{\text {prior }}$.

$$
\begin{gathered}
V_{\text {prior }}=\max _{a}\left(\sum_{i=1}^{7} \operatorname{Pr}\left(\Theta=\theta_{i}\right) v_{a}\left(\theta_{i}\right)\right) \\
a=1,2
\end{gathered}
$$

300 In words, $\mathrm{V}_{\text {prior }}$ quantifies the best the decision-makers can do with the current uncertainty (no MT data has 301 been collected), which are reflected in the prior probabilities $\operatorname{Pr}\left(\Theta=\theta_{i}\right) . \mathrm{V}_{\text {prior }}$ identifies which decision alternative gives on average the best outcome (done through the $\max _{a}$ ). When considering a specific location for geothermal exploration, these prior probabilities should come from a geologist and/or other experts with knowledge of the geologic structure and history. For our base case (column $a$ of Table 2), we assume $\operatorname{Pr}(\Theta>30)=26 \%$, higher than all other categories. The lowest steam flow category is assigned at $15 \%$ probability. An alternate is included to demonstrate the influence of the prior on the final VOI: reflecting an increase drilling uneconomic wells. The column b) of Table 2 is the alternate prior, where the probability of the lowest steam flow class has increased to $40 \%$ and the greatest steam flow class is now only $10 \%$.

Returning to the lottery example, when $\mathrm{V}_{\text {prior }}$ is 0 , the decision-maker should "not participate in the lottery" (i.e. don't drill) given the current state of information. $\mathrm{V}_{\text {prior }}=0$ tells the decision-maker that the decision alternative to "do nothing" will yield the higher outcome on average. $\mathrm{V}_{\text {prior }}=0$ reflects the potential for large losses when you "participate in the lottery" or drill to produce a geothermal reservoir. The decision-maker would be wise to participate in the lottery only when $V_{\text {prior }}>0$. The two different $V_{\text {prior }}$ 's for each of the prior probabilities are shown in Table 3, which use the value outcomes of Table 2. For the prior probabilities based on the steam flow data, $\mathrm{V}_{\text {prior }}=\$ 151,550$. This is a relatively high value since the drilling bias in the data deems the steam flow category of $>30 \mathrm{~kg} / \mathrm{s}$ as the most probable. $\mathrm{V}_{\text {prior }}$ decreases to $\$ 0$ for the alternative prior. Intuitively this makes sense since this prior reflects the higher probabilities for a "dry hole" or costly outcome.

\subsection{VOI $_{\text {perfect }}$ : Upper bound on the value of information}

The value of perfect information can be calculated by substituting in $\mathrm{V}_{\text {perfect }}$ for the value with information $\left(\mathrm{V}_{\text {with information }}\right)$ in Equation 1. $\mathrm{VOI}_{\text {perfect }}$ assumes that an information source exists that will always identify the correct economic viability category $\theta_{i}$ without errors. Like $V_{\text {prior }}, V_{\text {perfect }}$ only depends on the prior uncertainty and potential gains/losses of the problem.

$$
V_{\text {perfect }}=\sum_{i=1}^{7} \operatorname{Pr}\left(\Theta=\theta_{i}\right)\left(\max _{a} v_{a}\left(\theta_{i}\right)\right)
$$


326 Here, we see that for each steam flow rate category $\theta_{\mathrm{i}}$, we can choose the best decision alternative $a$ (this is

327

328

329

330

331

332

333

334

335

336

337

338

339

340

reflected in $\max _{a}$ being calculated before the weighted average). With perfect information, we always know when the reservoir is uneconomic, and therefore we will always choose not to participate in the lottery. Thus, we remove the chance of loss by collecting perfect information. With our current state of information, we would not enter the lottery when the potential losses were greater than the likelihood of any possible gains. But with a flawless information source to allow us to avoid these losses, we may choose to participate in the lottery. Since it assumes error-free information, the $\mathrm{VOI}_{\text {perfect }}$ quantity will give an upper bound on what we could expect for any information source. For the example using prior probabilities based on the data (Table 1a), $V_{\text {perfect }}=\$ 248,550$. For the alternative prior (Table $1 \mathrm{~b}$ ), $\mathrm{V}_{\text {perfect }}=\$ 116,500$ since there is perceived to be a much lower probability of a high-valued outcome $(\operatorname{Pr}(\Theta>30)=10 \%)$. Following Equation 1

$$
V O I_{\text {perfect }}=\max \left(V_{\text {perfect }}-V_{\text {prior }}, 0\right)
$$

Thus, $\operatorname{VOI}_{\text {perfect }}=\$ 97,000$ and $\$ 116,500$ given the two respective $\mathrm{V}_{\text {prior }}$ 's $(\$ 151,550$ and $\$ 0)$. Thus, the upper bound of what information can bring is with the alternative prior, since there is a larger chance for a large economic loss.

\subsection{VOI imperfect $_{\text {Results: Different Clay Cap Interpretations }}$}

Now we consider imperfect MT data and we estimate its reliability when distinguishing between the seven different possible steam flow categories $\theta_{\mathrm{i}}$. The data is from a specific location, and we are using it to generate the required information posterior $\left(\operatorname{Pr}\left(\Theta=\theta_{i} \mid G=g_{j}\right)\right)$, which influences VOI, but everything else (priors, value outcomes, etc.) is completely unrelated to the location and settings of the actual data set. The information posterior $\operatorname{Pr}\left(\Theta=\theta_{i} \mid G=g_{j}\right)$ (Equation 5) is the "misinterpretation rate" used to calculate the value with imperfect information $\mathrm{V}_{\text {imperfect. }}$.

$$
V_{\text {imperfect }}=\sum_{j=1}^{J} \operatorname{Pr}\left(G=g_{j}\right)\left\{\max _{a}\left[\sum_{i=1}^{7} \operatorname{Pr}\left(\Theta=\theta_{i} \mid G=g_{j}\right) v_{a}\left(\theta_{i}\right)\right]\right\}
$$

Here, the posterior accounts for how often one may incorrectly infer a steam flow category given the inverted electrical conductance. The posterior is used to weigh the averaged outcome of each alternative and category combination $v_{a}\left(\theta_{i}\right)$. Since the decision is made after conductivity data has been collected, the best alternative $\left(\max _{a}\right)$ is chosen given the interpreted category. Lastly, $\mathrm{V}_{\text {imperfect }}$ is weighted by the marginal probability $\operatorname{Pr}\left(G=g_{j}\right)$ (also in Equation 5), which describes how often any of the particular inverted resistivities occur relative to other conductivity bins. 
Table 3: Table of nominal Vimperfect and VOIimperfect for the 2 clay cap interpretations (columns)

for 2 different priors (rows).

\begin{tabular}{|l|c|c|c|}
\hline Prior Probability: & Clay Cap defined by threshold: & 0.12 Siemens $/ \mathrm{m}$ & $0.10 \mathrm{Siemens} / \mathrm{m}$ \\
\hline \multirow{3}{*}{ According to data } & $\mathrm{V}_{\text {prior }}$ & $\$ 151,550$ & $\$ 151,550$ \\
\cline { 2 - 4 } & $\mathrm{V}_{\text {imperfect }}$ & $\$ 162,580$ & $\$ 171,500$ \\
\cline { 2 - 4 } & $\boldsymbol{V O I}_{\text {imperfect }}$ & $\mathbf{\$ 1 1 , 0 3 0}$ & $\$ 19,950$ \\
\hline \multirow{3}{*}{ Alternate prior } & $\mathrm{V}_{\text {prior }}$ & $\$ 0$ & $\$ 0$ \\
\cline { 2 - 4 } & $\mathrm{V}_{\text {imperfect }}$ & $\$ 48,775$ & $\$ 37,090$ \\
\cline { 2 - 4 } & $\boldsymbol{V O I}_{\text {imperfect }}$ & $\$ \mathbf{4 4 8 , 7 7 5}$ & $\$ 37,090$ \\
\hline
\end{tabular}

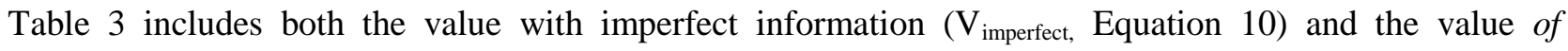
imperfect information ( $\left.\mathrm{VOI}_{\text {imperfect }}\right)$. The value of imperfect information $\left(\mathrm{VOI}_{\text {imperfect }}\right)$ is calculated using

Equation 1 where now the $\mathrm{V}_{\text {imperfect }}$ (Equation 10) is used in place of the generic term of $\mathrm{V}_{\text {with information }}$.

$$
\text { VOI } I_{\text {imperfect }}=\max \left(V_{\text {imperfect }}-V_{\text {prior }}, 0\right)
$$

As expected, all the $\mathrm{VOI}_{\text {imperfect }}$ 's estimates are lower than their respective $\mathrm{VOI}_{\text {perfect }}$ 's $(\$ 97,000$ and $\$ 116,500)$. This demonstrates how the highest value outcome will not be realized because of the imperfectness of the data that can mislead the decision maker about the economic viability of the reservoir. The three $\mathrm{VOI}_{\text {imperfect }}$ results are not significantly different from each other for the two prior probability cases. For the prior case based on the data, which places a high likelihood of steam flows greater than $30 \mathrm{~kg} / \mathrm{s}$, the $\mathrm{VOI}_{\text {imperfect }}$ assessed from the clay cap defined at $0.1 \mathrm{~S} / \mathrm{m}$ is slightly higher (than that of the $0.12 \mathrm{~S} / \mathrm{m}$ clay cap). This can be explained by the posterior being much closer to zero for conductances $>250$ S. Posteriors closer to zero reflect how the conductance for this category has less overlap with the others, and therefore, the information in the conductance data is more useful for discerning between the steam flow categories. This reverses for the alternate prior, as now the emphasis is on the lowest steam flow category.

\subsection{VOI for determining the next location to drill}

This section describes how the information posteriors can be used to determine new locations for drilling that may have higher likelihood of success. For brevity, this section will only describe how this technique 
is applied to the clay cap defined at $0.12 \mathrm{~S} / \mathrm{m}$. Figure 11 displays the conductance ( $\mathrm{S}$ ) of the clay cap for the clay cap interpreted only with a $0.12 \mathrm{~S} / \mathrm{m}$ threshold. For this particular field, a future drilling campaign is considered in an area covered by the current MT inversion, but no drilling has taken place and therefore, no existing steam flow information is available. We can plot the posteriors according to the MT inversion model and look specifically at the area under consideration for future drilling. This may guide future well locations by using the past performance of MT to locate high steam flow.

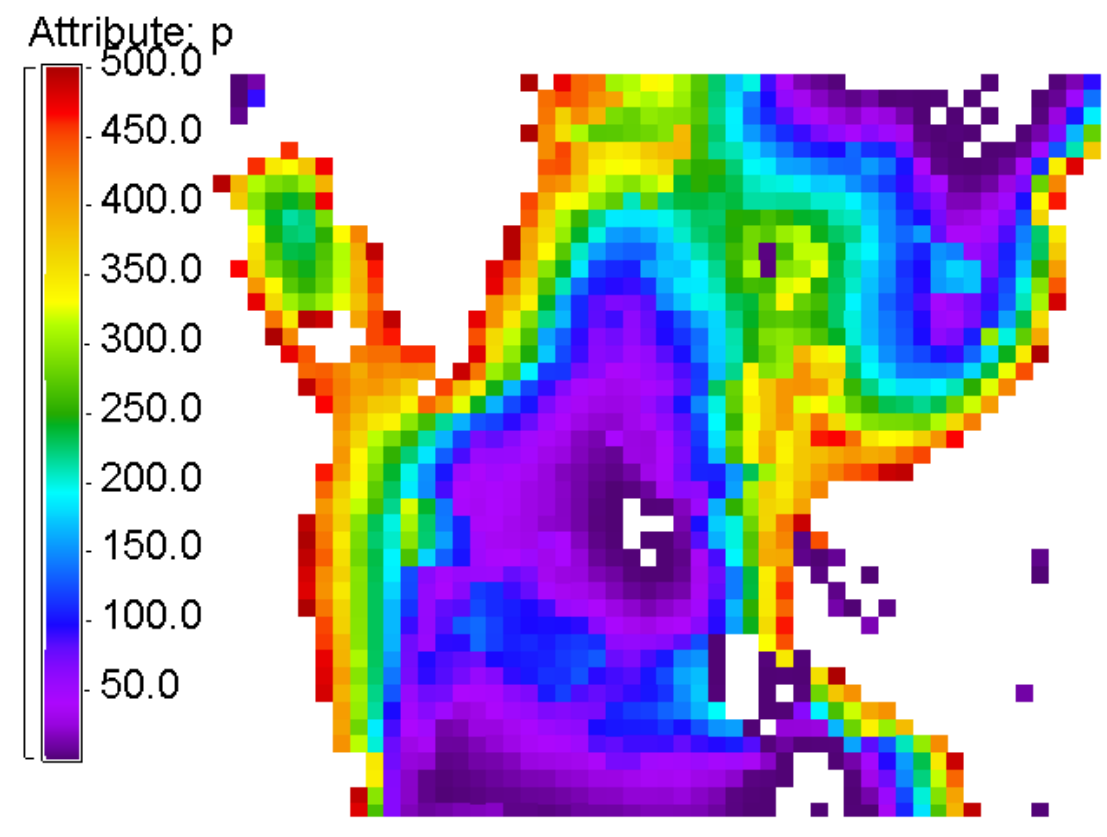

Figure 11: Conductance (S) of clay cap interpreted with $0.12 \mathrm{~S} / \mathrm{m}$ threshold (plane view).

In the case where the posterior strongly identifies the highest steam flow category (as in the case of $S<40$ $\mathrm{S}), \operatorname{Pr}\left(\Theta=\theta_{i} \mid G=g_{j}\right) \approx 100 \%, i=7$. But if no conductance range (bin) exists that exclusively (or close to exclusively) can identify the higher steam flow category, the posterior will reflect this conductance bin contains low information content. For example, in Figure 9 the posterior value for the conductance bin of $\sim 140-150 \mathrm{~S}$ is almost evenly split across 6 different steam flow categories: $\operatorname{Pr}\left(\Theta=\theta_{i} \mid G=g_{j}\right) \approx 17 \%, i=$ $1,2,3,4,5,7$.

Figure 12 contains the sum of the posteriors for steam categories $i \geq 4(\Theta \geq 15 \mathrm{~kg} / \mathrm{s})$ for the conductance at that location (see Figure 11): $\sum_{i=4}^{7} \operatorname{Pr}\left(\Theta=\theta_{i} \mid G=g_{j}\right)$. Thus, by mapping back the posterior of each conductance bin, the posterior values provides some spatial guidance on where drilling future development wells may produce a high valued result, given the relationship of current production with the interpreted MT data. Of course, if a different steam flow rate was deemed economical, the posterior could be recalculated to only include those desired categories (e.g. $i \geq 6$ ). 


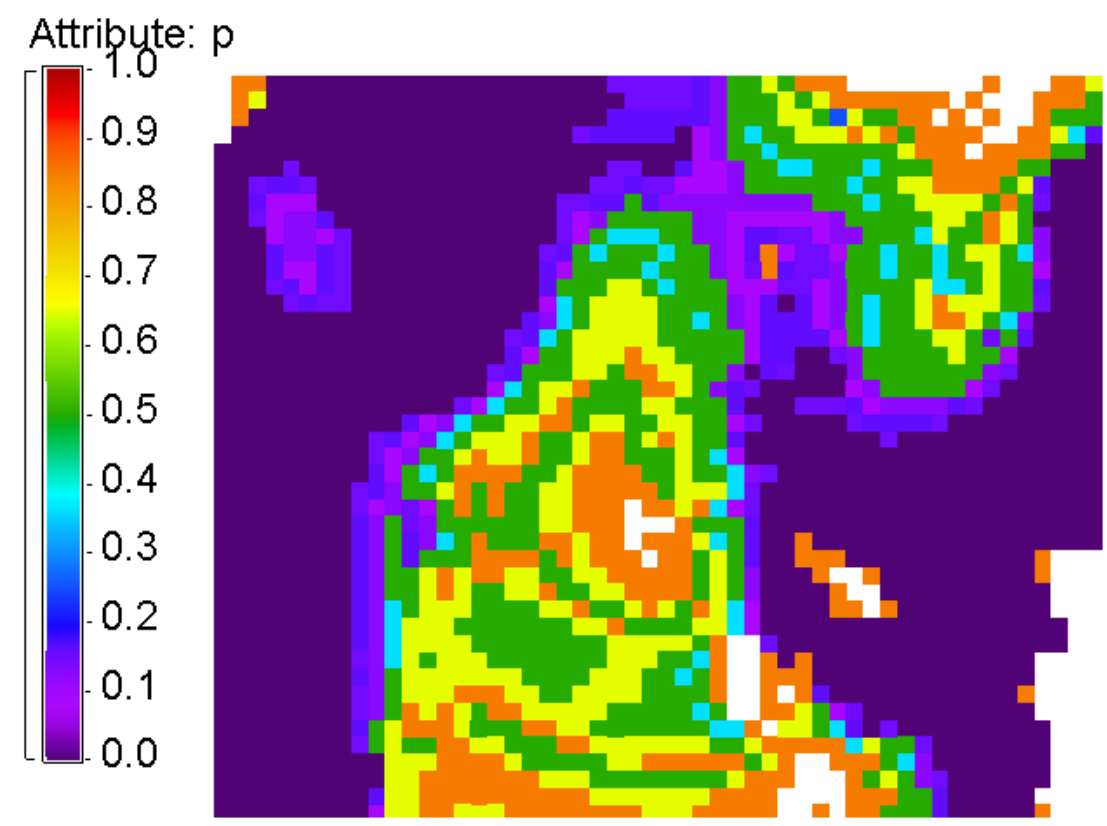

400 Figure 12: $\left.\operatorname{Pr}\left(\Theta>15 \mid G=g_{j}\right)\right):$ Probability of $\theta>15 \mathrm{~kg} / \mathrm{s}$ given conductance of Figure 11 and 401 posterior calculated from Figure 9.

\section{DISCUSSION \& CONCLUSIONS}

403 VOI is used to determine whether a particular type of data is worth acquiring and thus, the VOI must be 404 calculated before the intended data is collected. We use a calibrated data set (electrical conductivity model 405 from MT that is colocated with steam flow measurements) to estimate the past performance of MT to 406 delineate the boundaries of the clay cap. Therefore, we assume that this VOI will be used to decide whether 407 or not to purchase MT data at analog field sites in the future. Specifically, we estimated the reliability of the 408 data to reveal the principal uncertainty to the decision: $\theta_{\mathrm{i}}$ representing steam flow for our example. In turn, 409 we described how the value of imperfect information could be calculated given this reliability. We use a 410 hypothetical decision scenario of "to drill or not" to define the other drivers of VOI: the prior probability, 411 the value outcomes of Table 1. These would need to be refined in order to use these VOI estimates to 412 determine whether or not to purchase the information.

413 This study indicates that the different interpretations of the clay cap do not greatly impact the assessed VOI 414 of the MT data. This should not be construed as a universal result for multiple geophysical interpretations 415 and VOI, but as an outcome unique to the constructs of this example including the prior, value outcomes 416 and the data. From a decision analysis stand point, the different $\mathrm{VOI}_{\text {imperfect }}$ 's are indistinguishable since 417 they are within $\$ 9,000$ and $\$ 11,000$ of each other for the two different priors, and therefore, the decision to 418 purchase MT or not would be the same given the result of these three $\mathrm{VOI}_{\text {imperfect }}$ 's. It is also possible that 419 other parameters deduced from MT and related to the clay cap (such as elevation of the base of the conductor) could have a stronger relationship with high steam flow. 
We also used VOI to aid in determining future drilling locations. These relied on the information posteriors calculated for the clay cap interpretation and the value outcomes of Table 1. The posterior map can be used by the operators and local experts to provide information on how they may prioritize and target their next well(s).

Finally, we would like to note how this methodology allows for multiple 3D inversions, as this will often be the case. Multiple inversions could be treated by "increasing" the data in the conductance 'bins,' or handling them as distinct interpretations. Stochastic inversions that produce PDF's (probability distribution functions) for each location would also augment the conductance bins or provide multiple interpretations, VOI estimates and posterior maps. This technique could easily be extended to other types of data, such as seismic AVA (amplitude versus angle) and oil production.

\section{ACKNOWLEDGMENTS}

The authors express their gratitude to the U.S. Department of Energy - Geothermal Technologies Office, who funded this project and to Chevron who provided the data and expertise in processing it.

\section{REFERENCES}

Bratvold, R.B., Bickel, J.E., Risk, A., and Lohne, H.P., 2009, Value of Information in the Oil and Gas Industry : Past, Present, and Future: Society of Peteroleum Engineers:Reservoir Evaluation \& Engineering, p. 11-14, doi: 10.2118/110378-PA.

Cumming, W., 2009, Geothermal resource conceptual models using surface exploration data: PROCEEDINGS, Thirty-Fourth Workshop on Geothermal Reservoir Engineering, p. SGP-TR-187.

Gunderson, R., Cumming, W., Astra, D., and Harvey, C., 2000, Analysis of smectite clays in geothermal drill cuttings by the methylene blue method: for well site geothermometry and resistivity sounding correlation, in Proceedings World Geothermal Congress, p. 1175-1181.

Karlsdóttir, R., Vilhjálmsson, A., Árnason, K., and Beyene, A., 2012, Peistareykir Geothermal Area , Northern Iceland 3D Inversion of MT and TEM Data: , p. 173.

Newman, G.A., and Alumbaugh, D.L., 2000, Three-dimensional magnetotelluric inversion using non-linear conjugate gradients: Geophysical Journal International, v. 140, p. 410-424, doi: 10.1046/j.1365-246x.2000.00007.x.

Pratt, J., Raiffa, H., and Schlaifer, R., 1995, Introduction To Statistical Decision Theory: Cambridge, MA, The Massachusets Institute of Technology Press.

Rejeki, S., Rohrs, D., Nordquist, G., and Fitriyanto, A., 2010, Geologic Conceptual Model Update of the Darajat Geothermal Field , Indonesia: Proceedings World Geothermal Congress 2010, p. 25-29.

Trainor-Guitton, W.J., Hoversten, G.M., Nordquist, G., and Intani, R.G., 2015, Value of information analysis using geothermal field data : accounting for multiple interpretations \& determining new drilling locations, in Society of Exploration Geophycists Expanded Abstracts, p. 1996-2000.

Trainor-Guitton, W.J., Hoversten, G.M., Ramirez, A., Roberts, J., Juliusson, E., Key, K., and Mellors, R., 2014, The value of spatial information for determining well placement: A geothermal example: Geophysics, v. 79, p. 1-15. 
456 Trainor-Guitton, W.J., Ramirez, A., Ziagos, J., Mellors, R., and Roberts, J., 2013a, An Initial Value Of Information ( 457 VOI ) Framework For Geophysical Data Applied To The Exploration Of Geothermal Energy, in 458 PROCEEDINGS, Thirty-Eighth Workshop on Geothermal Reservoir Engineering, Stanford University, 459 Stanford, California, February 11-13, 2013 SGP-TR-198,

460 Trainor-Guitton, W.J., Ramirez, A., Ziagos, J., Mellors, R., Roberts, J., Juliusson, E., and Hoversten, G.M., 2013b, 461 Value of Spatial Information for Determining Geothermal Well Placement: Geothermal Resources Council 462 Transactions, p. 1-18.

463 Ussher, G., Harvey, C., Johnstone, R., and Anderson, E., 2000, Understanding the resistivities observed in geothermal 464 systems, in Proceedings World Geothermal Congress, p. 1915-1920.

465 